\title{
Physicochemical Properties of Starches from Two Different Yam (Dioscorea Opposita Thunb.) Residues
}

\author{
Yugao Wang ${ }^{1}$, Liming Zhang ${ }^{1 *}$, Xinglin $\mathrm{Li}^{2}$ and Wenyuan $\mathrm{Gao}^{3}$ \\ ${ }^{1}$ Key Laboratory of Industrial Microbiology; Ministry of Education; Tianjin University of Science and Technology; \\ 300457; Tianjin - China. ${ }^{2}$ College of Biotechnology; Tianjin University of Science and Technology; 300457; \\ Tianjin - China. ${ }^{3}$ School of Pharmaceutical Science and Technology, Tianjin University; 30072; Tianjin - China
}

\begin{abstract}
The starches obtained from two different yam residues, which were treated with alkali(starch-A) or enzyme (starch-E), were studied and compared with yam starch isolated using ordinary method (starch-O) for morphological, crystalline pattern, thermal, and pasting properties. The results revealed that the amylose content of three starches ranged from 19.47 to $22.17 \%$. The granule surfaces of starch-A and starch-E were as smooth as that of starch-O. The crystalline pattern of the three starches was a C-type. The transition temperatures $\left(T_{o}, T_{p}\right.$ and $\left.T_{c}\right)$ varied from 70.11 to $73.64,79.23$ to 81.74 , and 84.30 to $86.65{ }^{\circ} \mathrm{C}$, respectively. The starch-E showed the highest $\Delta H_{\text {gel }}$, followed by the starch-A, while it was lowest for the starch-O. According to the viscosity measurement, starch-O had the lowest pasting temperature, highest peak viscosity and breakdown viscosity, which were contrary to those of starch-E.
\end{abstract}

Key words: Yam starch, Yam residue, Thermal, Crystallinity, Pasting property

\section{INTRODUCTION}

Yam (Dioscorea opposita Thunb.) is widely distributed in China and has been used as an important invigorant in traditional Chinese medicine for many years. It has been used for nourishing liver and kidney, promoting the production of the body fluids and benefiting the lung and invigorating the kidney and spleen (Zuo and Tang, 2003). Yam contains many chemical components such as mannan, allantoin, dopamine, batatasine, phytic acid, abscisin II, amino-acids, glucoprotein, choline, cholesterol, ergosterol, campesterol, saponins, starch, non-starch polysaccharide etc (Nie et al., 1993; Zhao et al., 2003).
In recent years, more and more attention has been paid on the activity and extraction process of the active substances contained in yam. Zhao et al., (2003) studied the structure and antitumor activity of RDPS-I polysaccharide from yam. Zhao et al., (2009) reported the extraction technology of water-soluble components in yam using alkali proteinase. However, the starch which accounted for $20 \sim 60 \%$ of total biomass of yam was ignored and wasted during the isolation and separation of the low molecular weight bioactive ingredients, resulting in the waste of resources and contamination of the environment.

Starch, an important carbohydrate in higher plants, is widely used in food, pharmacy and other industry such as thickening and gelling agent as

*Author for correspondence: zhanglmd@yahoo.com.cn 
well as pharmaceutical excipient (Demiate et al., 2001; Judith et al., 2005), deserves detailed investigation to understand better its structural and functional characteristics. The physicochemical, morphological, thermal and crystal properties of starch obtained from yam using ordinary method have been reported (Wang et al., 2006). However, the properties of starch obtained from the yam residues, which have been produced during the isolation of bioactive ingredients by several methods, have been not full investigated yet. To fully use the source of medicinal plant and protect the environment, the properties of starch in the yam residue deserves deep study.

The purpose of this study was to investigate the properties of starch obtained from the yam residues which were treated with alkali and enzyme treatments and compared with that of yam starch isolated with ordinary method. The properties of starch samples were obtained using scanning electron microscope (SEM), x-ray powder diffractometer (XRD), differential scanning calorimeter (DSC) and Brabender viscograph. With the obtained results, it would be possible to precisely evaluate the availability and provide sufficient parameters to make full use of yam residue.

\section{MATERIAL AND METHODS}

\section{Reagents and materials}

The yam flours were received from Wanxi Medicine Co., Ltd. (Henan, China), which were made by milling the dried yam slices with a hammer mill and then sieving under laboratory sieve of $600 \mu \mathrm{m}$ aperture size.

For yam residues treated with alkali, the proximate composition $\%$ on dry weight basis was found to be 92.0 starch, 2.6 protein, 0.6 fat, 2.5 fiber and $2.3 \mathrm{ash}$. For the yam residues treated with enzyme, the proximate composition on $\%$ dry weight basis was as follows: 93.3 starch, 1.4 protein, 0.5 fat, 2.3 fiber and 2.5 ash.

The alkaline proteinase $(140000 \mathrm{U} / \mathrm{g})$ was provided by Novozymes Enzyme Co. (Tianjin, China).

\section{Preparation of yam starch using ordinary method (starch-O)}

The native starch was isolated following the method described by Wang et al. (2006). The yam flour was washed and sieved with a $150 \mu \mathrm{m}$ mesh sifter. After depositing, the supernatant was removed by suction and the settled starch layer was resuspended in distilled water. After seven or eight cycles of depositing and resuspending repeatedly, the slurry containing starch was centrifuged at $3000 \mathrm{r} / \mathrm{min}$ for $20 \mathrm{~min}$. The supernatant was discarded and the upper nonwhite layer was removed. Ethanol (70\%) was added in order to remove the low molecular weight compounds. The white layer was resuspended in distilled water and recentrifuged 3 5 times. The white layer obtained was dried in a convection oven at $50{ }^{\circ} \mathrm{C}$ until weight constancy. The dried material was milled and sieved with a 75 $\mu \mathrm{m}$ screen to get the starch flour.

\section{Preparation of starch isolated from the yam residue treated with alkali (starch-A)}

At first, the yam flours were treated according to the modified method described by Haba et al., (2005). One hundred grams dried yam flours was suspended in $1 \mathrm{~L}$ distilled water in a reaction pot and the $\mathrm{pH}$ value was adjusted with $0.1 \mathrm{M} \mathrm{NaOH}$ to about 9.0. Then the starch suspension was incubated in a water bath at $40{ }^{\circ} \mathrm{C}$ with a working churn and kept at constant temperature for $4 \mathrm{~h}$. After that, the suspension was centrifuged at 3000 $\mathrm{r} / \mathrm{min}$ for $10 \mathrm{~min}$. The supernatant was spilled and the solid layer was resuspended in distilled water. The following steps were the same as the method mentioned in the preparation of starch-O.

Preparation of starch isolated from the yam residue treated with enzyme (starch-E)

At first, the dried yam flours were treated following the method described by Zhao et al., (2009). One hundred grams dried yam flour and $7000 \mathrm{U}$ alkali proteinase were suspended in $1 \mathrm{~L}$ distilled water in a reaction pot and the $\mathrm{pH}$ value was adjusted with $1 \mathrm{M} \mathrm{Na}_{2} \mathrm{CO}_{3}$ to 9.5 . Then the suspension was incubated in a water bath at $45^{\circ} \mathrm{C}$ with a working churn and kept at constant temperature for $1.5 \mathrm{~h}$. After that, the suspension was centrifuged at $3000 \mathrm{r} / \mathrm{min}$ for $15 \mathrm{~min}$. The supernatant was spilled and the solid layer was resuspended in distilled water. The following steps were the same as the method mentioned in the preparation of starch-O.

\section{Determination of amylose content}

The apparent amylose contents were determined by the amylose-iodine complex procedure with modification (Fathat et al., 1999). The results were 
obtained using a spectrophotometer (Shimadzu UV-1700, Tokyo, Japan). The starch sample of $0.1000 \mathrm{~g}$ was suspended in a solution containing 1 $\mathrm{mL} \mathrm{99 \%} \mathrm{(v/v)} \mathrm{ethanol} \mathrm{and} 9 \mathrm{~mL}$ of $1 \mathrm{M} \mathrm{NaOH}$ and heated in a water bath of $95{ }^{\circ} \mathrm{C}$ for $10 \mathrm{~min}$. Then the starch solution was diluted with deionized water to $100 \mathrm{~mL}$. Five milliliter of the solution was transferred into $100 \mathrm{~mL}$ flask, and $50 \mathrm{~mL}$ deionized water and $1 \mathrm{~mL}$ iodine solution was transferred at the same time. After that the volume was made up to $100 \mathrm{~mL}$ with deionized water. Five milliliter of $0.09 \mathrm{M} \mathrm{NaOH}$ solution was transferred into another flask as a blank. Then the value of absorbance was obtained at $620 \mathrm{~nm}$. The experiments were performed in triplicate.

\section{Determination of water-binding capacity (WBC)}

WBC of samples was determined using the method of Yamazaki (1953), as modified by Medcalf and Gilles (1965). A suspension of $5 \mathrm{~g}$ starch (dry weight) in $75 \mathrm{~mL}$ distilled water was agitated at $25{ }^{\circ} \mathrm{C}$ for $1 \mathrm{~h}$ and centrifuged at 3000 $\mathrm{r} / \mathrm{min}$ for $10 \mathrm{~min}$. The free water was removed from wet starch, drained for $10 \mathrm{~min}$ and wet starch was weighed.

\section{Determination of swelling power and solubility}

The value of swelling power and solubility were determined according to the method of Yuan et al., (2007). Fifty milliliter of $2 \%(w / w)$ starch (dry basis) suspension was prepared and measured exactly. Then the starch suspension was incubated in a water bath at different temperatures from 65 to $95{ }^{\circ} \mathrm{C}$ with a working churn and kept at constant temperature for $30 \mathrm{~min}$. Subsequently, the sample was cooled at room temperature and put into centrifuge tubes with cap. Then these tubes were centrifuged at $3000 \mathrm{r} / \mathrm{min}$ for $20 \mathrm{~min}$. The supernatant was dried at a convection oven at $50{ }^{\circ} \mathrm{C}$, and then the sediment weight and solid content of the supernatant were weighed. The equations of solubility and swelling power are as fellows:

$$
\begin{aligned}
& \text { Solubility (S) }(\%)=\frac{A}{W} \times 100 \% \\
& \text { Swelling power }(\%)=\frac{P \times 100}{W(100-S)}=\frac{P}{W(1-S / 100)}
\end{aligned}
$$

Where $A$ refers to solid content of the supernatant; $W$ refers to the dry weight of starch samples; $P$ refers to the sediment weight.

\section{Morphological Properties}

The dried yam starch samples were mounted on a glass board covered with double-side tape and gilded with gold in a Polaron E-5200 coating unit (Polaron equipment, Watford, England). Then the prepared starch granule morphology was studied using Philips XL-30 ESEM scanning electron microscope (Philips, Eindhoven, Holland). These images of samples were received at $20.0 \mathrm{kV}$ accelerating voltage and magnified 500 times.

\section{X-ray diffractometry}

The structures of starch samples were carried out using wide-angle $\mathrm{X}$-ray diffraction. They were recorded with a Rigaku D/max 2500 X-ray powder diffractometer (Rigaku, Tokyo, Japan). These dried powder samples were scanned using $\mathrm{Cu} \mathrm{K \alpha}$ radiation $(\lambda=1.54056 \AA)$ at $40 \mathrm{kV}$ and $150 \mathrm{~mA}$. The scanning region of the angles $(2 \theta)$ was from 3 to $50^{\circ}$ at a scanning speed of $6 \% \mathrm{~min}$. The scan steps size of 0.02 were used with a dwell time of $0.2 \mathrm{~s}$. The degree of crystallinity of the samples was quantitatively estimated following the method of Nara and Komiy (1983).

\section{DSC}

Thermal characteristics of starch samples were studied by using a differential scanning calorimeter (NETZSCH, Germany) equipped with a thermal analysis station. Each of the starch samples (3.5 mg, dry weight) was loaded into an aluminium pan (Mettler, ME-27331) and distilled water was added with the help of a Hamilton microsyringe to achieve a starch-water suspension containing $70 \%$ water. These pans were hermetically sealed, equilibrated at room temperature for $1 \mathrm{~h}$ and heated from 20 to $120{ }^{\circ} \mathrm{C}$ at a heating rate of $10{ }^{\circ} \mathrm{C} / \mathrm{min}$. The melting enthalpy and the temperature axis were calibrated with indium. Each test was carried out with an empty pan as a reference and the onset temperature of gelatinization $\left(T_{\mathrm{o}}\right)$, the peak temperature $\left(T_{\mathrm{p}}\right)$, the gelatinization temperature at conclusion $\left(T_{\mathrm{c}}\right)$, and melting enthalpy $(\Delta H)$ were recorded. The range of gelatinization temperature (R) was computed as $\left(T_{\mathrm{c}}-T_{\mathrm{o}}\right)$ and the peak height index (PHI) was calculated as the ratio $\Delta H /$ $\left(T_{\mathrm{p}}-T_{\mathrm{o}}\right)$ (Krueger et al., 1987; Vasanthan and Bhatty, 1996). 


\section{Determination of Pasting Properties}

The pasting properties of the samples were measured using a Brabender Viscograph-E Measurement and Control Systems (Brabender OHG, Duisburg, Germany). Thirty grams (dry basis) of starch sample and $470 \mathrm{~mL}$ of distilled water $(6 \%)$ were mixed and transferred into the cup of Brabender viscograph. The starch suspension was heated from 35 to $95{ }^{\circ} \mathrm{C}$ at $1.5^{\circ} \mathrm{C} / \mathrm{min}$ and kept for $30 \mathrm{~min}$ at $95{ }^{\circ} \mathrm{C}$, then it was cooled down to $50{ }^{\circ} \mathrm{C}$ at a rate of $1.5^{\circ} \mathrm{C} / \mathrm{min}$ and held at $50{ }^{\circ} \mathrm{C}$ for $30 \mathrm{~min}$. Then pasting cures were evaluated for the peak viscosity (PV), hot paste viscosity at $95{ }^{\circ} \mathrm{C}(\mathrm{HPV})$, viscosity at $50{ }^{\circ} \mathrm{C}$ (CPV), breakdown viscosity (BV) and setback viscosity (SV).

\section{RESULTS AND DISCUSSION}

\section{Amylose content}

The amylose contents of yam starch obtained with ordinary method and starches separated from the yam residues were obtained by using a spectrophotometer. Significant differences in the amylose contents were observed (Table 1). On dry weight basis, the starch-O had the highest apparent amylose content $(22.17 \%)$ while the starch-E had the lowest apparent amylose content (19.47\%). The lower amylose content of the starches obtained from alkali and enzyme treated residues could be due to the mild hydrolysis of amylose in the solutions of high $\mathrm{pH}$ value.

\section{Water-Binding Capacity (WBC)}

Table 1 showed that the WBC of starch samples was slightly different, lowest for the starch-E and highest for the starch-O. High WBC of starches could be attributed to the involvement of a less proportion of the hydroxyl groups in forming the hydrogen and covalent bonds between starch chains than with water (Hoover and Sosulski, 1986).

Table 1- Water-binding capacity, amylose content, and degree of crystallinity of starch-O, starch-A and starch-E.

\begin{tabular}{cccc}
\hline Samples & WBC (\%) & Amylose content (\%) & Degree of crystallinity (\%) \\
\hline Starch-O & $129.37 \pm 2.31$ & $22.17 \pm 0.63$ & $23.70 \pm 1.64$ \\
Starch-A & $126.14 \pm 1.87$ & $20.76 \pm 0.47$ & $26.88 \pm 1.76$ \\
Starch-E & $117.43 \pm 2.79$ & $19.47 \pm 0.72$ & $27.12 \pm 2.21$ \\
\hline
\end{tabular}

\section{Swelling Power and Solubility}

Fig. 1 showed that the swelling power of three different samples were slightly different and the starch-O always had the highest swelling power, followed by the starch-A. The swelling power of starch has been reported to depend on the waterbinding capacity of starch molecules by hydrogen bonding (Lee and Osman, 1991). Fig. 2 showed that the starch-A had the highest solubility from 65 to $80^{\circ} \mathrm{C}$, whereas the starch-O dissolved best from 85 to $95^{\circ} \mathrm{C}$. The swelling power and solubility of samples increased obviously as the temperature increased, but the differences among different samples in the same temperature were indistinctive. This indicated that two different treatments had little influence on yam starch due to its stable granule structure.

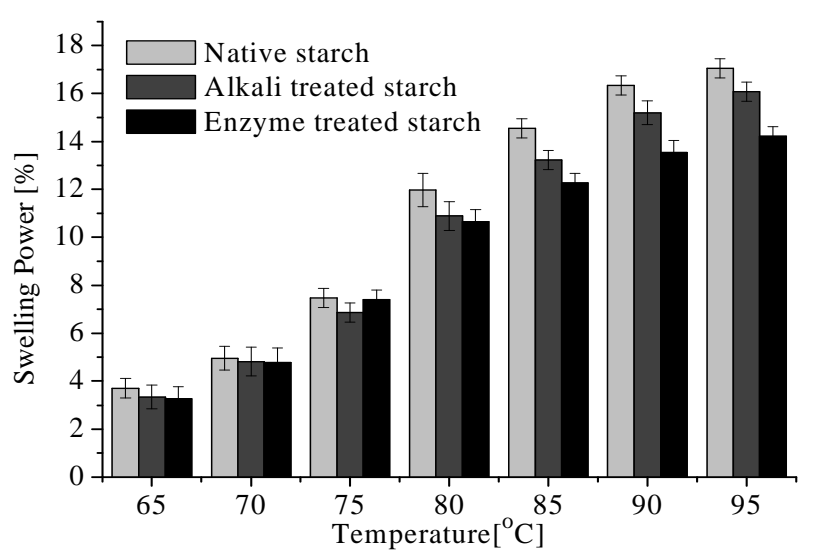

Figure 1 - Swelling power profiles of native yam starch, alkali treated starch and enzyme treated starch. 


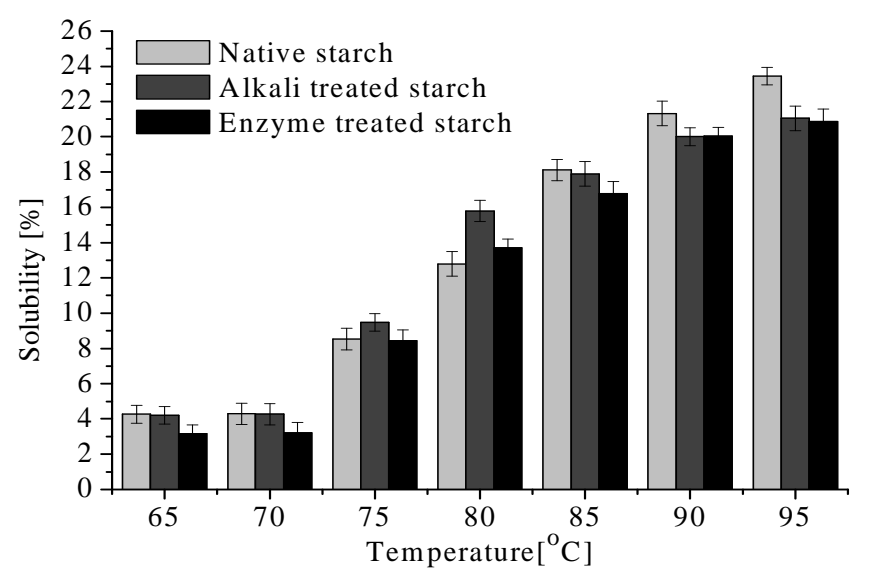

Figure 2 - Solubility profiles of native yam starch, alkali treated starch and enzyme treated starch.

\section{Starch Granule Morphology}

The granule shape, size and morphology of samples are shown in Fig. 3. The SEMs of three starch samples showed the presence of starch granules, from small to large and round or cuboidal to oval or irregular, with diameter ranges between 5 20 and 20 50 $\mu \mathrm{m}$ for small and large granules, respectively. Also, the surface of the starch granules of three samples all appeared to be smooth with no evidence of any fissures. This indicated that the alkali and enzyme treatments had little impact on the granule surface of yam starch.

\section{X-ray diffractometry}

The crystal characterizations of starch granules have often been carried out using X-ray diffraction patterns, which have been classified as $\mathrm{A}, \mathrm{B}$ or $\mathrm{C}$ pattern. According to the current models of starch granule, parallel double amylopectin molecules result in the formation of crystalline regions, while amylose molecules result in the formation of amorphous regions in the starch structure (Cheetham and Tao, 1998). The X-ray diffractograms of the three starch samples are presented in Fig. 4. The corresponding degree of crystallinity calculated from the ratio of diffraction peak area and total diffraction area are shown in Table 1. The diffraction spectra showed four strong diffraction peaks at 5.6, 14.8, 17.0 and $23.1^{\circ}$ of $2 \theta$. Of all the diffraction peaks showed in the Fig. 4, the peaks at around the 5.6 and $17.0^{\circ}$ of $2 \theta$ were characteristic of B-type pattern. The other two peaks at 14.8 and $23.1^{\circ}$ of $2 \theta$ were indicative of the A-type pattern. Thus, the three starches separated from the yam with different treatments were classified as C-type, which was a mixture of A and B types.

The degrees of crystallinity of three starch samples are shown in Table 1. Generally speaking, the degree of crystallinity of starch is depending on its amylose content. The higher the amylose content, the lower is the degree of crystallinity of starch. The starch-O had the highest amylose content and the lowest degree of crystallinity while the starchE showed the lowest amylose content and highest degree of crystallinity.

\section{Differential Scanning Calorimetry}

Starch gelatinization was characterized by DSC because of its accuracy. As known from the literature (Biliaderis et al., 1980), starch granule is a semi-crystalline entity. When heated with steam it swells and an endothermic process is noted. At the same time, the order of crystallinity becomes disordered. The results of DSC analysis of starch samples are summarized in Table 2. The transition temperatures $\left(T_{\mathrm{o}}, T_{\mathrm{p}}\right.$, and $\left.T_{\mathrm{c}}\right)$, range $\left(T_{\mathrm{c}}-T_{\mathrm{o}}\right)$, enthalpies of gelatinization $\left(\Delta H_{\text {gel }}\right)$ and peak height indices (PHI) of starches isolated with the three different methods differed significantly. 

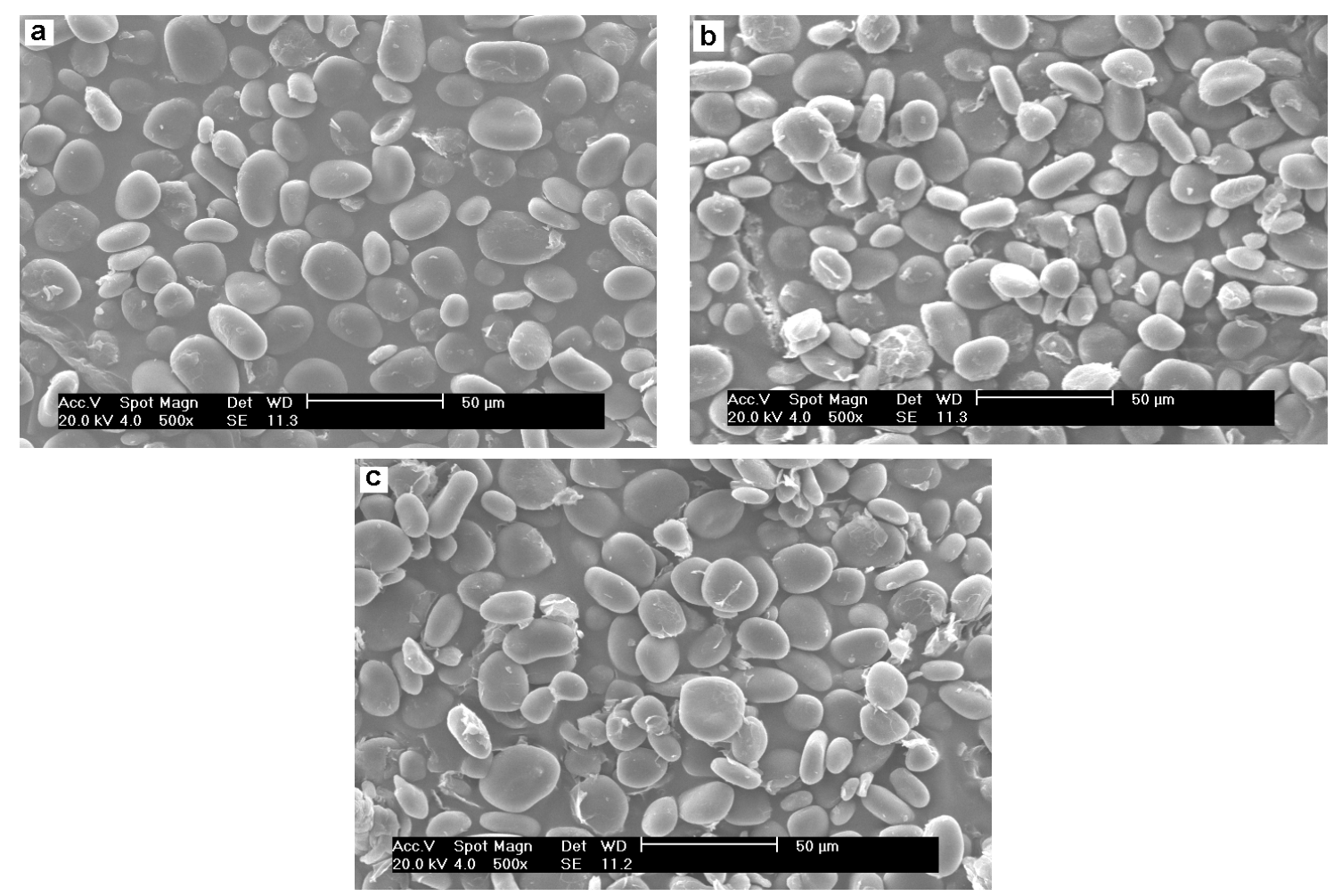

Figure 3 - Scanning electron micrographs of three starch samples: (a) native starch, (b) alkali treated starch, and (c) enzyme treated starch.

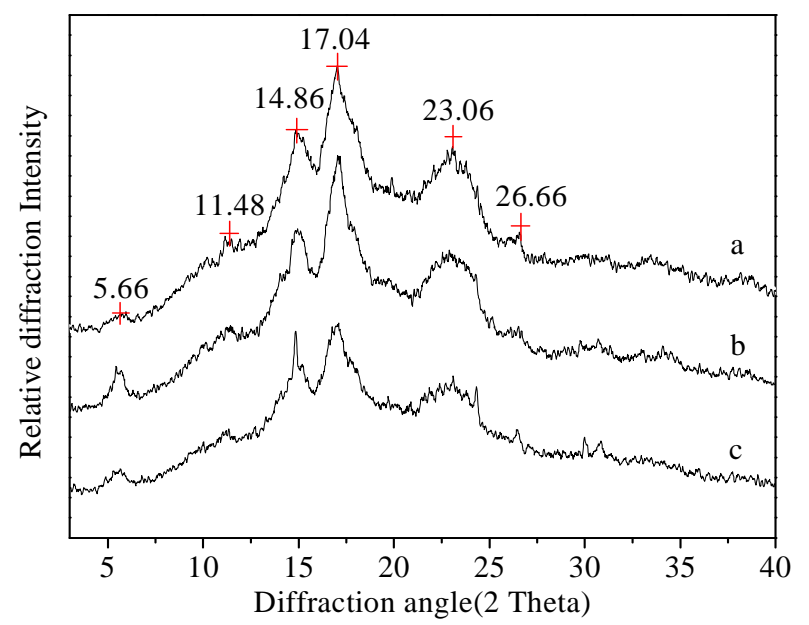

Figure 4 - X-ray diffraction of the three starch samples: (a) native starch, (b) alkali treated starch, and (c) enzyme treated starch.

Table 2 - Thermal properties of native yam starch, alkali treated starch and enzyme treated starch.

\begin{tabular}{lcccccc}
\hline Samples & $\boldsymbol{T}_{\mathbf{o}}{ }^{\mathbf{a}}\left({ }^{\mathbf{0}} \mathbf{C}\right)$ & $\boldsymbol{T}_{\mathbf{p}}{ }^{\mathbf{b}}\left({ }^{\circ} \mathbf{C}\right)$ & $\boldsymbol{T}_{\mathbf{c}}{ }^{\mathbf{c}}\left({ }^{\mathbf{o}} \mathbf{C}\right)$ & $\boldsymbol{\Delta H}_{\mathbf{g e l}}{ }^{\mathbf{d}}(\mathbf{J} / \mathbf{g})$ & $\mathbf{P H I}$ & $\mathbf{R}^{\mathbf{f}}$ \\
\hline Native starch & 70.11 & 79.23 & 84.30 & 10.54 & 1.16 & 14.19 \\
Alkali treated starch & 72.57 & 81.74 & 85.42 & 11.96 & 1.30 & 12.85 \\
Enzyme treated starch & 73.64 & 81.13 & 86.65 & 12.04 & 1.61 & 13.01 \\
\hline
\end{tabular}

${ }^{\mathrm{a}} T_{\mathrm{o}}=$ onset temperature. ${ }^{\mathrm{b}} T_{\mathrm{p}}=$ peak temperature. ${ }^{\mathrm{c}} T_{\mathrm{c}}=$ conclusion temperature. ${ }^{\mathrm{d}} \Delta H_{\text {gel }}=$ gelatinization enthalpy. ${ }^{\mathrm{e}} \mathrm{PHI}=$ peak height index $\Delta H_{\text {gel }} /\left(T_{\mathrm{p}}-T_{\mathrm{o}}\right) .{ }^{\mathrm{f}} \mathrm{R}=$ range of gelatinization temperature $\left(T_{\mathrm{c}}-T_{\mathrm{o}}\right)$ 
Compared with other starches, the starch-E showed the highest gelatinization temperature $\left(T_{0}\right.$, $T_{\mathrm{p}}, T_{\mathrm{c}}$ ) what indicated that it had a higher level of crystallinity, while the starch-O had the lowest gelatinization temperature which could be due to the lowest degree of crystallinity of its granules (Tester and Morrison, 1990). The starch-E showed the highest $\Delta H_{\text {gel }}$ value $(12.04 \mathrm{~J} / \mathrm{g})$, followed by the starch-A $(11.96 \mathrm{~J} / \mathrm{g})$, while it was lower for the starch-O $(10.54 \mathrm{~J} / \mathrm{g})$. Previous study has postulated that the increasing $\Delta H_{\text {gel }}$ value indicates the decreasing amylose content of the three starches (Iouchi et al., 1984). The starch-O had the highest $\mathrm{R}$ value, while the starch-A had the minimum value. The differences in $R$ value among the starch samples could be due to the presence of crystalline regions of different strength in the granules (Banks and Greenwood, 1975). PHI is a measure of uniformity in gelatinization and is the ratio of $\Delta H_{\text {gel }}$ to the gelatinization temperatures range. PHI of starch-E was the highest, whereas that of starchA was the lowest. These different thermal properties could be attributed to the effect of alkali and enzyme treatments on the amylopectin content, the degree of crystallinity and the presence of crystalline regions of different strength in the granules of starch samples (Singh and Singh, 2001).

\section{Determination of pasting properties}

The pasting properties of starch samples determined by Brabender Viscograph are presented in Table 3. The pasting temperature (PT), peak viscosity (PV), hot-pasting viscosity (HPV), cool-pasting viscosity (CPV), setback viscosity (SV) and breakdown viscosity (BV) of the three starches differed significantly. The starch-E had the highest PT $\left(83.6^{\circ} \mathrm{C}\right)$ and the lowest PV (119 BU), while the starch-O had the lowest PT $\left(81.1^{\circ} \mathrm{C}\right)$ and the highest PV (221 BU). The higher degree of crystallinity of starch-E was probably responsible for the higher PT. The viscosity of starch-O decreased from 221 to 175 BU during the holding period, whereas the other starch samples did not display much shear thinning. The CPVs increased after cooling down and the increased CPVs indicated that the paste could be more resistant to shearing and could form a more rigid gel (Zhang et al., 2005), which suggested a pronounced tendency to retrogradation. Setback is defined as the degree of re-association between the starch molecules involving amylose (Charles et al., 2004). The SVs of starch-O, starch-A and starch-E were 26 BU, 29 $\mathrm{BU}$ and $28 \mathrm{BU}$, respectively, being slightly different. The starch-O showed the highest BV (46 BU), followed by the starch-A (6 BU), while it was lower for the starch-E. Higher BV suggests that the sample has undergone a higher degree of swelling and subsequent disintegration (Abera and Sudip, 2003), and the evidence is received from the highest swelling power of native starch (Fig. $1)$.

Table 3 - Pasting properties of native yam starch, alkali treated starch and enzyme treated starch.

\begin{tabular}{lcccccc}
\hline Sample & $\left.\mathbf{P T}^{\mathbf{b}} \mathbf{(}^{\mathbf{0}} \mathbf{C}\right)$ & $\mathbf{P V}^{\mathbf{c}}(\mathbf{B U})$ & $\mathbf{H P V} \mathbf{( B U})$ & $\mathbf{C P V}^{\mathbf{e}}(\mathbf{B U})$ & $\mathbf{S V}^{\mathbf{f}}(\mathbf{B U})$ & $\mathbf{B V}^{\mathbf{g}}(\mathbf{B U})$ \\
\hline Native starch & 81.1 & 221 & 175 & 202 & 26 & 46 \\
Alkali treated starch & 82.4 & 127 & 121 & 150 & 29 & 6 \\
Enzyme treated starch & 83.6 & 119 & 115 & 144 & 28 & 4 \\
\hline
\end{tabular}

${ }^{\mathrm{a}}$ Values were means of three determinations $(\mathrm{n}=3)$. ${ }^{\mathrm{b}} \mathrm{PT}=$ pasting temperature. ${ }^{\mathrm{c}} \mathrm{PV}=$ peak viscosity. ${ }^{\mathrm{d}} \mathrm{HPV}=$ hot-paste viscosity. ${ }^{\mathrm{e}} \mathrm{CPV}=$ cool-paste viscosity. ${ }_{\mathrm{f}} \mathrm{SV}=$ setback viscosity. ${ }^{\mathrm{g}} \mathrm{BV}=$ breakdown viscosity. 


\section{CONCLUSIONS}

The sarches separated from Chinese yam residues after the different treatments showed significant changes in physicochemical, morphological, thermal, crystal and pasting properties. The starch$\mathrm{O}$ had the highest amylose content, while the starch-E had the lowest level of amylose. The three different starch samples showed different water-binding capacities, swelling powers and solubility. The surfaces of the starch-A and starchE were as smooth as starch-O granules. This indicated that the yam starch isolated from yam residue could also be used as a material of many products such as porous starch. The starch-E had the higher degree of crystallinity as well as the higher gelatinization temperature and enthalpy. However, the starch-O had the lower degree of crystallinity as well as the lower gelatinization temperatures and enthalpy. The crystal type of the three starches was a C-type pattern. Brabender viscosities showed that the peak viscosity and breakdown viscosity of starches obtained from the yam residues treated with alkali and enzyme were lower than those of native starch. The pasting temperatures of starch-O, starch-A and starch-E were $81.1,82.4$ and $83.6{ }^{\circ} \mathrm{C}$, respectively. Although many properties of starches obtained from two different yam residues showed significant differences to the native starch, the basic structure of starch granules was not changed, which indicated that these starches could also be used instead of native yam starch available commercially.

\section{ACKNOWLEDGEMENTS}

This work was granted by the applied foundation and leading technology research program of Tianjin city (No. 08JCZDJC15300). The authors are grateful to Bailing Zhou, Academy of Agricultural Sciences of Sanxi, China, for help with the determination of pasting properties.

\section{REFERENCES}

Abera, S. and Sudip, K. R. (2003), Comparison of physicochemical and functional properties of cassava starch extracted from fresh root and dry chips. Starch/Stärke, 55, 287-296.
Banks, W. and Greenwood, C. T. (1975), Starch and its components. Edinburgh University Press, Edinburgh, UK.

Biliaderis, C. G., Maurice, T. J. and Vose, J. R. (1980), Starch gelatinization phenomena studied by differential scanning calorimetry. Journal of Food Science, 45, 1669-1674.

Charles, A. L., Chang, Y. H.; Ko, W. C., Sriroth, K. and Huang, T. C. (2004), Some physical and chemical properties of starch isolates of Cassava genotypes. Starch/Stärke, 56, 413-418.

Cheetham, N. W. H. and Tao, L. (1998), Solid state NMR studies on the structural and conformational properties of natural maize starches. Carbohydrate Polymers, 36, 277-284.

Fathat, I. A., Tunde, O. and Roger, N. J. (1999), Characterization of starches from West African Yam. Journal of the Science of Food and Agriculture, 79, 2106-2111.

Haba, P. F., Ding, X. L. and Zhang, L. F. (2005), Protein concentrate and starch from polished rice: preparation and characterization. Food Research and Development, 26, 12-15.

Hoover, R. and Sosulski, F. (1986), Effect of cross linking on functionalproperties of legume starches. Starch/Stärke, 38, 149-155.

Iouchi, N., Glover, D. V., Sugimoto, Y. and Fuwa, H. (1984), Developmental changes in starch properties of several endosperm mutants of maize. Starch/Stärke, 36, 8-12.

Demiate, I. M., Oetterer, M., Wosiacki, G.(2001), Characterization of Chestnut (Castanea sativa, Mill) Starch for Industrial Utilization. Brazilian Archives of Biology and Technology, 44, 69-78.

Krueger, B. R., Knutson, C. A., Inglett, G. E., and Walker, C. E. (1987), A differential canning calorimetry study on the effect of annealing on gelatinization behavior of corn starch. Journal of Food Science, 52, 715-718.

Lee, Y. E. and Osman, E. M. (1991), Correlation of morphological changes of rice starch granules with rheological properties during heating in excess water. Journal of Korean Agricultural Chemical Society, 34, 379-385.

Medcalf, M. J., and Gilles, K. A. (1965), Wheat starches. I. Comparison of physicochemical properties. Cereal Chemistry, 42, 558-568.

Nara, S. and Komiy, T. (1983), Studied on the relationship between water-saturated state and crystallinity by the diffraction method for moistened potato starch. Starch/Stärke, 35, 407-410.

Nie, G. H., Zhou, K. F., Dong, X. H., and Zhang, C. (1993), Research advances of yam. Chinese Traditional Herbal Drugs, 24, 158-160.

Singh, J. and Singh, N. (2001), Studies on the morphological, thermal and rheological properties of starch separated from some Indian potato cultivars. Food Chemistry, 75, 67-77. 
Tester, R. F.; and Morrison, W. R. (1990), Swelling and gelatinization of cereal Starches. I. Effects of amylopectin, amylose and lipids. Cereal Chemistry, 67, 551-557.

Vasanthan, T. and Bhatty, R. S. (1996), Physicochemical properties of small and large granule starches of waxy, regular, and high amylase barleys. Cereal Chemistry, 73, 199-207.

Wang, S. J., Liu, H. Y., Gao, W. Y., Chen, H. X., Yu, J. G., and Xiao, P. G. (2006), Characterization of new starches separated from different Chinese yam (Dioscorea opposita Thunb.) cultivars. Food Chemistry, 99, 30-37.

Wang, S. J., Yu, J. L., and Gao, W. Y. (2006), New starches from traditional Chinese medicine (TCM) Chinese yam (Dioscorea opposita Thunb.) cultivars. Carbohydrate Research, 341, 289-293.

Yamazaki, W. T. (1953), An alkaline water retention capacity test for the evaluation of cookie baking potentialities of soft winter wheat flours. Cereal Chemistry, 30, 242-246.
Yuan, Y., Zhang, L. M., Dai, Y. J., and Yu, J. G. (2007), Physicochemical properties of starch obtained from Dioscorea nipponica Makino comparison with other tuber starches. Journal of Food Engineering, 82, 436-442.

Zhang, Z. T., Niu, Y. X., Eckhoff, S. R., and Feng, H. (2005), Sonication enhanced cornstarch separation. Starch/Stärke, 57, 240-245.

Zhao, G. H., Li, Z. X., and Chen, Z. D. (2003), Structural analysis and antitumor activity of RDPS-I polysaccharide from Chinese yam. Acta Pharmaceutica Sinica, 38, 37-41.

Zhao, X., Zhang L. M., and Wang L.L. (2009), A study on extraction technology of water-soluble components in yam using alkali proteinase. Fine Chemical, 26, 2832.

Zuo, Y. F., and Tang, D. C. (2003), Science of Chinese materia medica. Shanghai University of Traditional Chinese Medicine Press, Shanghai, China.

Received: September 02, 2009; Revised: February 03, 2010; Accepted: September 29, 2010. 